\title{
Androgen, progesterone, and FSH receptor polymorphisms in ovarian cancer risk and outcome
}

\author{
Agnieszka Honorata Ludwig ${ }^{1}$, Magdalena Murawska ${ }^{2}$, Grzegorz Panek ${ }^{3}$, \\ Agnieszka Timorek ${ }^{4}$ and Jolanta Kupryjanczyk ${ }^{1}$
}

Departments of ${ }^{1}$ Molecular Pathology, ${ }^{2}$ Biostatistics and ${ }^{3}$ Gynecologic Oncology, The Maria Sklodowska-Curie Memorial Cancer Center and Institute of Oncology, Roentgena 5, 02-781 Warsaw, Poland

${ }^{4}$ Chair and Department of Obstetrics, Gynecology and Oncology, IInd Faculty of Medicine, Warsaw Medical University and Brodnowski Hospital, Kondratowicza 8, 03-242 Warsaw, Poland

(Correspondence should be addressed to J Kupryjanczyk; Email: jkupry@ coi.waw.pl)

\begin{abstract}
Genes encoding hormone receptors are among candidate genes modulating the risk of ovarian cancer. We aimed to assess a frequency of PGRG + 331A, FSHRAla307Thr, and FSHRSer680Asn polymorphic variants, and the length of (CAG) $n$ and (GGN) $n$ repeat tracts in the androgen receptor gene $(A R)$ with respect to ovarian cancer risk and outcome. We genotyped 215 ovarian cancer patients and 352 unaffected control subjects. Statistical analysis was performed with the logistic regression model with adjustment for age. Clinical importance of the polymorphic variants was evaluated in multivariate models on 69 patients treated with taxane-platinum chemotherapy, with respect to TP53 status. Longer $A R(\mathrm{GGN}) n$ and (CAG) $n$ repeat tracts decreased the risk of ovarian cancer. For (GGN) n, each additional repeat decreased the risk by $17 \%(P=0.011)$ or $27 \%$ $(P=0.002)$, while the presence of at least 23 repeats decreased the risk by $41 \%(P=0.032)$ or $68 \%(P=0.008)$, for the shorter or longer allele respectively. The risk of disease was also decreased by $11 \%$ with each additional $(\mathrm{CAG}) n$ repeat $(P=0.006$ for the longer allele). FSHRAla307Ala or FSHRSer680Ser polymorphisms increased ovarian cancer risk by 1.8 times $(P=0.042)$. In all 69 patients, longer $A R(\mathrm{CAG}) n$ repeats decreased the risk of recurrence $(P=0.031)$. In the group with TP53 accumulation, longer $A R(C A G) n$ repeats decreased the risk of recurrence $(P=0.003)$ and death $(P=0.03)$, while the FSHRSer680Ser polymorphism increased the risk of recurrence $(P=0.037)$. Progesterone receptor polymorphisms analyzed did not show any associations. Our results support both the androgen and gonadotropin hypotheses of ovarian cancer development.
\end{abstract}

Endocrine-Related Cancer (2009) 16 1005-1016

\section{Introduction}

Ovarian cancer is the most lethal gynecologic malignancy. The highest ovarian cancer rates are reported from Northern Europe and Baltic countries. The highest mortality rate is observed in Lithuania, Denmark, Ireland, and UK (age standardized (world) - ASR(W) $\sim 9 / 100$ 000). In Poland, ovarian cancer is the fifth most often diagnosed cancer in women $(5.4 \%)$ and the fourth cause of cancer-related death (ASR(W) is 7/100 000).

The risk of ovarian cancer increases from the age of 35 and decreases after the age of 59. The probability that a woman will be diagnosed with ovarian cancer before the age of 80 years is estimated at $1.5 \%$ (Didkowska et al. 2007). The majority of ovarian cancer cases are sporadic. Familial cancer (about 10\%) may develop due to inherited mutations of highly penetrant $B R C A 1$ and BRCA2 genes. Much more common are low-penetrance genes that may account for a larger proportion of ovarian cancers in the general population (Wooster \& Weber 2003). Unfortunately, both high- and low-penetrance genes are difficult to identify.

One of the most well-known hypotheses of ovarian cancers development is the incessant ovulation hypothesis'; it says that ovarian cancer develops as a result of repeated disruption of ovarian surface 
epithelium (Fathalla 1971). The disruption may promote cellular proliferation and genetic instability. Other hypotheses postulate a direct involvement of endogenous hormones in ovarian cancer etiology. The 'gonadotropin hypothesis' (Cramer \& Welch 1983, Rao \& Slotman 1991) states that FSH and LH may be directly involved in the transformation of normal ovarian surface epithelium to a malignant one. The 'androgen hypothesis' (Risch 1998), the most commonly considered one, postulates that ovarian cancer risk is enhanced by excessive androgen stimulation, while it is decreased by progesterone stimulation.

Genes encoding hormone receptors are among candidate genes modulating the risk of ovarian cancer. Several single nucleotide polymorphisms (SNPs) and microsatellite polymorphic variants were detected in hormone receptor genes; some of them are common and may influence the receptor activity (Modugno 2004). In particular, two microsatellite polymorphic variants $(\mathrm{CAG}) n$ and $(\mathrm{GGN}) n$ repeats were found in exon 1 of the androgen receptor gene $(A R)$. It was shown on cell lines that the number of $(\mathrm{CAG}) n$ repeats can affect transactivation capabilities of the AR. The shorter allele forms are more active in transducing signals (Chamberlain et al. 1994). The functional significance of the (GGN)n repeat is still unknown.

With regard to FSH receptor (FSHR) gene, two out of five currently known exonic polymorphic sites are under extensive investigations. Both are SNPs located in exon 10, which is fundamental for signal transduction. G919A results in Ala or Thr at position 307, while G2039A results in Ser or Asn at position 680 in the protein. It was shown in patients undergoing IVF procedure that ovarian response to FSH stimulation was more efficient in individuals with AsnFSHR680Asn than with SerFSHR680Ser genotype (Perez Mayorga et al. 2000).

The progesterone receptor (PGR) protein is encoded by a single gene; it is present in two isoforms due to two transcriptional start sites. The $\beta$-isoform is a transcriptional activator and a mediator of cell proliferation, while the $\alpha$-isoform is a repressor of transcription. Recently, a new polymorphism in the promoter region of the $P G R$ gene has been identified in the position $+331(\mathrm{G}+331 \mathrm{~A})$. The $+331 \mathrm{~A}$ allele creates a unique transcription start site that increases PGR $\beta$-isoform synthesis. Thus, it can be responsible for increased cell proliferation and may contribute to cancer formation (De Vivo et al. 2002).

The purpose of the current study was to examine possible associations between genetic polymorphisms of the androgen ((CAG) $n$ and (GGN) $n$ repeats), FSH (FSHRAla307Thr, FSHRSer680Asn) and PGRs
$(\mathrm{PGRG}+331 \mathrm{~A})$ and ovarian cancer incidence in univariate setting. We show significant associations between polymorphisms in the androgen and FSH receptors and ovarian cancer risk. For the group of patients treated with taxane-platinum chemotherapy, we demonstrate associations between FSH receptor types and $\mathrm{AR}(\mathrm{CAG}) n$ repeat length and clinical endpoints.

\section{Materials and methods}

\section{Subjects}

A total of 567 individuals were genotyped. Two hundred and fifteen incident Polish-Caucasian women (from central Poland) diagnosed with epithelial ovarian cancer were enrolled in this study. The blood from patients was collected in two Warsaw area hospitals between the years 1995 and 2007. The Institute of Oncology is an oncology reference center that treats patients from a large area of central Poland and a fraction of patients from eastern Poland. The Bródnowski Hospital is Warsaw district hospital that treats patients from central Poland. Both the hospitals treat the majority of ovarian cancer patients from central Poland.

Among the patients, 157 (73\%) were diagnosed with a serous carcinoma, $5(2 \%)$ with a mucinous one, $9(4 \%)$ with an endometrioid one, $13(6 \%)$ with a clear cell one, $9(4 \%)$ with an undifferentiated carcinoma, and 22 (10\%) with another type of carcinoma. Three hundred and fifty-two anonymous unrelated Polish-Caucasian controls were identified from the same region. The controls were recruited in a blood donation center in Warsaw between November 2005 and November 2006. The control group comprised of consecutive women who agreed to take part in the analysis (response fraction unknown). Both patients and control subjects were enrolled in this study after giving informed consent (patients gave written informed consent). This study was approved by the bioethics committee of the Institute of Oncology. The control subjects had median age of 30 years (range 18-59). The median age of patients was 55 years (range 17-84).

Demographic characteristics of ovarian cancer cases and controls are reported in Table 1. We checked whether the population of cases analyzed was representative of the whole Polish ovarian cancer population with respect to patient's age. The results indicate that the distribution of cases in appropriate age intervals between the two groups is similar $(P=0.707$, Kolmogorov-Smirnoff test, Fig. 1). Because controls were younger than cases, we checked what was the lifetime risk of control subjects to develop cancer. If a probability of cancer incidence in our control subjects 
Table 1 Age characteristics of ovarian cancer cases and controls analyzed in this study

\begin{tabular}{lcc}
\hline Age (years) & Cases & Controls \\
\hline-20 & 1 & 33 \\
$21-25$ & 2 & 79 \\
$26-30$ & 2 & 69 \\
$31-35$ & 5 & 42 \\
$36-40$ & 8 & 37 \\
$41-45$ & 24 & 28 \\
$46-50$ & 35 & 28 \\
$51-55$ & 33 & 26 \\
$56-60$ & 23 & 10 \\
$61-65$ & 32 & - \\
$66-70$ & 29 & - \\
$71-75$ & 11 & - \\
$76-80$ & 4 & - \\
$81-85$ & 1 & - \\
\hline
\end{tabular}

was equal to the probability in the whole population, then before the age of 80 only 0.1 cancer diagnosis would occur in our control group. We do not have any additional information regarding body mass index, pregnancy and breast feeding history, fertility status (infertility treatment), oral contraceptive use, menstrual characteristics, gynecologic diseases, lifestyle characteristics such as alcohol consumption, smoking, physical activity, or other ovarian cancer risk factors either for cases or for controls.

Among cases, 69 patients were uniformly treated in gynecologic oncology units with standard taxaneplatinum regimens, as previously described (Kupryjańczyk et al. 2008). Taxol, given in a $24 \mathrm{~h}\left(135 \mathrm{mg} / \mathrm{m}^{2}\right)$ or $3 \mathrm{~h}$ infusion $\left(175 \mathrm{mg} / \mathrm{m}^{2}\right)$, or docetaxel $\left(75 \mathrm{mg} / \mathrm{m}^{2}\right)$ was followed by cisplatin $\left(75 \mathrm{mg} / \mathrm{m}^{2}\right)$ or carboplatin (AUC6). Follow-up time ranged from 9.8 to 99 months

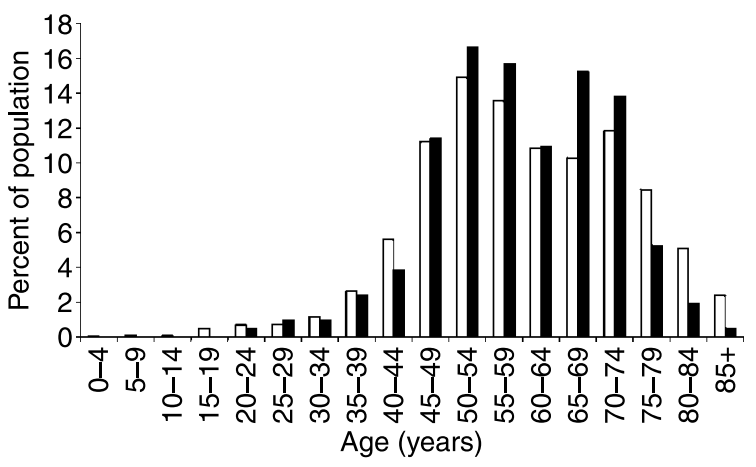

Figure 1 In this study, we analyzed 215 patients only and all of them came from central Poland. Therefore, we checked whether the age distribution in our group analyzed was representative of all ovarian cancer patients in Poland. White bars represent all ovarian cancer patients in appropriate age intervals, while black bars represent cases analyzed in this study. The age distribution in these two groups is similar $(P=0.707)$. (median 35). All surviving patients had at least a 2.5 year follow-up. In this group, we analyzed the influence of genetic and non-genetic factors on disease outcome.

Medical records were reviewed centrally and all tumors were uniformly reviewed histopathologically according to the World Health Organization criteria (Tavassoli \& Devilee 2003). The patients were carefully selected to meet several criteria, among them are an adequate staging procedure, no chemotherapy before staging laparotomy, International Federation of Gynecologists and Obstetricians stage IIB to IV disease, completed first-line chemotherapy, and tumor tissue from the first laparotomy available as previously described (Kupryjańczyk et al. 2008).

The clinicopathological characteristic of the group is shown in Table 2. Response to chemotherapy was evaluated retrospectively according to the World Health Organization response evaluation criteria (Miller et al. 1981). The evaluation was based on data from medical records describing the patient's clinical condition and the CA125 levels in the 3- to 4-week intervals. Complete remission (CR) was defined as the disappearance of all clinical and biochemical symptoms of ovarian cancer evaluated after completion of first-line chemotherapy and confirmed at 4 weeks. Within the CR group, we identified a platinum-sensitive group with disease-free survival (DFS) longer than 6 months. The other tumors (partial remission, progression $(\mathrm{P})$, and no change) as well as the CR group with DFS shorter than 6 months were described as resistant to cisplatin (Christian \& Trimble 1994, Table 2).

\section{Genotyping}

Genomic DNA was extracted from peripheral blood mononuclear cells with Qiagen genomic DNA mini kit according to the manufacturer's protocol. The specific polymorphic region of DNA was amplified by PCR with the application of Perkin Elmer PCR kit on a programmable thermal cycler (Biometra, Goettingen, Germany) with denaturation at $94{ }^{\circ} \mathrm{C}$, annealing at $50-62{ }^{\circ} \mathrm{C}$ (depending on the region, Table 3 ) and extension at $72{ }^{\circ} \mathrm{C}$ for 36 cycles, each step for $30 \mathrm{~s}$. The PCR was carried out in a volume of $12.5 \mu \mathrm{l}$.

For analysis of microsatellite variants in the $A R$ gene, the primers were fluorescently labeled (Table 3 ). Amplified samples were diluted in formamide loading buffer and denatured at $95{ }^{\circ} \mathrm{C}$. Fragments were run on denaturing polyacrylamide gels on the Applied Biosystems ABI PRISM 3100 and analyzed by Applied Biosystems Prism Genescan-automated fluorescence 
Table 2 Clinicopathological characteristics of taxane-platinumtreated subgroup

\begin{tabular}{ll}
\hline & $\mathbf{N}=69$ \\
\hline Age & \\
Range & $20-75$ \\
Mean (s.D.) & $54.11(11.2)$ \\
FIGO stage & \\
IIB-IIIB & $10(14 \%)$ \\
IIIC & $53(77 \%)$ \\
IV & $6(9 \%)$ \\
Residual tumor size (RT) & \\
0 & $13(19 \%)$ \\
$\leq 0.5$ cm & $23(33 \%)$ \\
O.5 RT $\leq 2$ cm & $18(26 \%)$ \\
$>2$ cm & $15(22 \%)$ \\
Histological type & \\
Serous & $55(80 \%)$ \\
Undifferentiated & $7(10 \%)$ \\
Other & $7(10 \%)$ \\
Tumor grade & \\
G2 & $9(13 \%)$ \\
G3 & $43(62 \%)$ \\
G4 & $17(25 \%)$ \\
TP53 accumulation & \\
Negative & $34(49 \%)$ \\
Positive & $35(51 \%)$ \\
Response to chemotherapy & \\
Complete remission & \\
Partial remission/no change & \\
Progression & $44(64 \%)$ \\
Sensitivity to treatment & $23(33 \%)$ \\
Platinum sensitive & $2(3 \%)$ \\
Platinum resistant & $38(55 \%)$ \\
Outcome & $31(45 \%)$ \\
AWD & $7(10 \%)$ \\
DOD & $12(17 \%)$ \\
DOC & $47 \%)$ \\
\hline
\end{tabular}

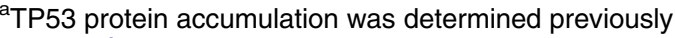
(Kupryjańczyk et al. 2008).

${ }^{b}$ We have combined these responses because it was not always possible to have objective measures of the disease in the retrospective study; NED, no evidence of disease; AWD, alive with disease; DOD, died of disease; DOC, died of other causes.

detection system. To independently validate the fragment length, a subset of samples was also analyzed by nucleotide sequencing. Control samples of known lengths were run on each plate to accurately determine the repeat number of CAG and GGN repeats.

For analysis of SNPs in the FSHR and PGR genes, we used the restriction fragment length polymorphism (RFLP) method. The amplified PCR products were digested with restriction enzymes (Fermentas, Vilnius, Lithuania; Table 3) at the optimized conditions for $2 \mathrm{~h}$ and then separated in $10 \%$ polyacrylamide gel (FSHRAla307Thr and FSHRSer680Asn) or 2\% agarose gel (PGRG+331A). After electrophoresis, the gels were stained with ethidium bromide and visualized under u.v. For quality purposes, $10 \%$ percent of cases for each polymorphic site were randomly selected (blindly with respect to original calls) and subjected to sequencing to confirm the PCR-RFLP results. The sequencing reactions were run on ABI PRISM 3100 Genetic Analyzer with the use of Big Dye Terminator chemistry. More than $95 \%$ of genotypes were callable.

For PGR and FSHR polymorphisms, all samples $(N=567,100 \%)$ were successfully genotyped. For the CAG-AR polymorphism, $97.6 \%$ of cases and $100 \%$ of controls were successfully amplified. For the GGN-AR polymorphism, $192(89.3 \%)$ case samples and 332 (94.3\%) control samples were successfully genotyped. Genotyping failures were considered as missing data.

\section{Statistical analysis}

The AR transcriptional activity decreases linearly across the entire CAG spectrum and this may also be the case for GGN spectrum. We analyzed $A R$ gene repeat polymorphisms as a continuous variable in logistic regression models that were fitted separately for CAG-1 (shorter allele), CAG-2 (longer allele), GGN-1 (shorter allele), GGN-2 (longer allele), and the average of both alleles (Average-CAG or AverageGGN). This approach assumes that each one-unit increment in CAG or GGN repeat length is related to a constant proportional change in relative risk. We also analyzed repeat polymorphisms as a categorical variable. The median value of the CAG and GGN repeat variables for the entire cohort was used as a cutoff point. We analyzed whether the risk of development of ovarian cancer decreased in groups with longer alleles. In all models, correction for age was considered. The age variable was categorized using median cut-off point. A similar analysis was performed for (categorical) variables describing polymorphisms in the FSHR and PGR genes.

Hardy Weinberg equilibrium was checked among cases, controls, and in the whole studied group. All polymorphisms were in Hardy Weinberg equilibrium $(P>0.05)$.

For the subgroup of taxane-platinum-treated patients, overall survival (OS) and DFS time analyses were performed using the multivariate Cox proportional hazards model. The response to chemotherapy was evaluated with the multivariate logistic regression model. The backward selection technique was used to select significant predictors. Variables not significant at 0.1 were stepwise removed from the model.

Initial multivariate models included the following variables: age of patients (categorized on median: 54 years), FIGO stage (IIIC-IV versus IIB-IIIB), 
Table 3 Primer sequences, annealing temperatures, sizes of the amplified products, names of restriction enzymes, and the band sizes after digestion with restriction enzymes for the analyzed polymorphic sites

\begin{tabular}{|c|c|c|c|c|c|}
\hline & Primer sequences & $\begin{array}{l}\text { Annealing } \\
\text { temperature } \\
\left({ }^{\circ} \mathrm{C}\right)\end{array}$ & $\begin{array}{l}\text { Product } \\
\text { size }(b p)\end{array}$ & $\begin{array}{l}\text { Restriction } \\
\text { enzyme }\end{array}$ & Band sizes (bp) \\
\hline \multirow[t]{3}{*}{ FSHR Ala307Thr } & $\begin{array}{c}\text { F: 5'-GCT-CTG-AGC-TTC- } \\
\text { ATC-CAA-TTT-G-3' }\end{array}$ & 55 & 120 & Eam1105I & $\mathrm{Thr} / \mathrm{Thr}-70+31+19$ \\
\hline & $\begin{array}{l}\text { R: } 5^{\prime} \text {-CTC-TGC-TGT-AGC- } \\
\text { TGG-ACT-CAT-T-3' }\end{array}$ & & & & Thr/Ala $-101+70$ \\
\hline & & & & & Ala/Ala $-101+19$ \\
\hline \multirow[t]{3}{*}{ FSHR Ser680Asn } & $\begin{array}{l}\text { F: } 5^{\prime} \text {-CCC-AAA-TTT-ATA- } \\
\text { GGA-CAG-3' }\end{array}$ & 50 & 114 & BseNI & Ser/Ser $-86+28$ \\
\hline & $\begin{array}{l}\text { R: } 5^{\prime} \text {-GAG-GGA-CAA-GTA- } \\
\text { TGT-AAG-TG-3' }\end{array}$ & & & & Ser/Asn $-114+86$ \\
\hline & & & & & Asn/Asn - 114 \\
\hline \multirow[t]{3}{*}{$P G R G+331 A$} & $\begin{array}{c}\text { F: } 5^{\prime} \text {-GAG-AGC-TTC-ACA- } \\
\text { GCA-TGC-ACG-3' }\end{array}$ & 58 & 206 & BspLI & $G G-149+57$ \\
\hline & $\begin{array}{c}\text { R: } 5^{\prime} \text {-GTA-GTA-ATT-GTT- } \\
\text { AGG-AGA-TCT-CGT-CT-3' }\end{array}$ & & & & $\mathrm{GA}-206+149+57$ \\
\hline & & & & & $A A-206$ \\
\hline $\mathrm{AR}(\mathrm{CAG}) n$ repeat & $\begin{array}{l}\text { F: } 5^{\prime} \text {-FAM-TCC-AGA-ATC- } \\
\text { TGT-TCC-AGA-GCG-TGC-3' }\end{array}$ & 62 & - & - & - \\
\hline & $\begin{array}{c}\text { R: 5'-GCT-GTG-AAG-GTT- } \\
\text { GCT-GTT-CCT-CAT-3' }\end{array}$ & & & & \\
\hline AR $(\mathrm{GGN}) n$ repeat & $\begin{array}{c}\text { F: } 5^{\prime}-\text { Hex-TCC-TGG-CAC-ACT- } \\
\text { CTC-TTC-AC-3' } \\
\text { R: 5'-ATC-AGG-TGC-GGT- } \\
\text { GAA-GTC-GCT-TTC-C-3' }\end{array}$ & 60 & - & - & - \\
\hline
\end{tabular}

F, forward; R, reverse.

residual tumor size $(\mathrm{RT}:>2, \leq 2$ and $>0.5$, and $\leq 0.5 \mathrm{~cm}$ vs 0 ), histological tumor type (serous versus other), and grade (3 vs 2 and 4 vs 2), categorized CAG and GGN repeat variables, categorical polymorphisms in the FSHR and PGR genes.

Survival probability estimates for OS and DFS were calculated using the Kaplan-Meier method. Significant variables obtained from the multivariate Cox's models were compared using log-rank test. The proportional hazards assumption was checked using Schoenfeld's residuals. Median follow-up was estimated using reversed Kaplan-Meier method. Associations between genetic and non-genetic categorical variables for this subgroup of patients were assessed using two-sided Fisher's exact test. Statistical significance was determined according to the conventional $P$ of $<0.05$.

\section{Results}

\section{Risk of disease analysis}

Analysis of repeat polymorphisms in the AR gene The distribution of AR (CAG) $n$ and (GGN) $n$ repeat numbers for the shorter and longer alleles among ovarian cancer cases and controls is shown in Fig. 2.
(CAG)n repeats. Allele lengths for (CAG)n repeats ranged from 7 to 38 . In the analysis of (CAG) $n$ repeats as a continuous variable, each additional repeat on the longer allele (CAG-2), as well as in the average of both alleles (Average-CAG), was associated with risk reduction by $11 \%$ (Table 4 ). No such association was observed for the shorter allele (CAG-1). The same analysis performed in the group of serous carcinomas gave results slightly beyond the border of significance for CAG-2 only $(P=0.063)$.

Binary categories of $(\mathrm{CAG}) n$ repeat were created with the cut-off point equal to 20 repeats for the shorter allele, 23 for the longer one, and 22 for the average of the two alleles; however, the associations with ovarian cancer risk were not significant (Table 4).

(GGN)n repeats. Allele lengths for $(\mathrm{GGN}) n$ repeats ranged from 11 to 24 . In the analysis of $(\mathrm{GGN}) n$ repeats as a continuous variable, each additional repeat decreased the risk of ovarian cancer by about $16 \%$ for the shorter allele (GGN-1), 26\% for the longer allele (GGN-2), and 25\% for the average of both alleles (Average-GGN; Table 4). The respective values for serous ovarian carcinomas were $15 \%$ $(P=0.035,95 \%$ CI $(0.73 ; 0.99)), 31 \% \quad(P=0.009$, 

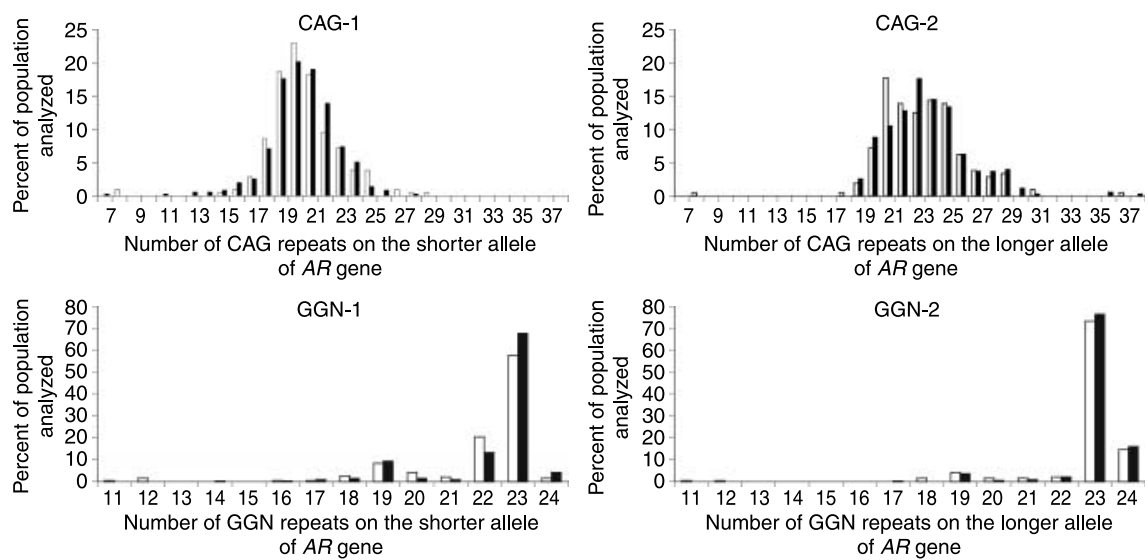

Figure 2 The repeat number of both CAG and GGN polymorphisms was analyzed on both alleles. The figure shows the distribution of $A R \mathrm{CAG}$ and GGN repeat number for the shorter and longer alleles among ovarian cancer cases (white) and controls (black).

$95 \%$ CI $(0.53 ; 0.91))$, and $26 \%(P=0.01,95 \%$ CI $(0.60 ; 0.93))$ for GGN-1, GGN-2, and for the Average-GGN.

(GGN)n repeats were categorized on median (23 repeats) for both alleles and for average of them. The presence of at least 23 repeats decreased the risk of ovarian cancer by $41-68 \%$ depending on the analysis. The strongest association with risk reduction and the highest risk reduction was observed for the longer allele (GGN-2; Table 4). The respective values for serous ovarian carcinomas were $40 \%(P=0.051,95 \%$ CI $(0.36 ; 1.00)), 70 \%$
$(P=0.015,95 \%$ CI $(0.11 ; 0.79))$, and $43 \%(P=0.033$, $95 \%$ CI $(0.34 ; 0.96))$ for GGN-1, GGN-2, and the Average-GGN.

\section{Analysis of polymorphisms in the FSHR and PGR genes}

The sizes of amplified products and the band sizes after digestion with appropriate restriction enzymes are shown in Table 3. Table 5 shows the frequency of the polymorphic variants in the FSHR and PGR gene-studied regions. The RFLP patterns of FSHRAla307Thr, FSHRSer680Thr, and PGRG + 331A are shown in Fig. 3.

Table 4 Results from univariate logistic models for (CAG) $n$ and (GGN) $n$ repeats treated as continuous or categorical variables, and for single nucleotide polymorphisms (SNPs) in the FSHR and PGR genes with adjustment for age (categorized on median: 41 years)

\begin{tabular}{|c|c|c|}
\hline Variable & OR $(95 \% \mathrm{Cl})$ & $\boldsymbol{P}$ \\
\hline \multicolumn{3}{|c|}{$\begin{array}{l}(C A G)_{n} \text { repeat polymorphism in the } A R \text { gene } \\
\text { Continuous variable }\end{array}$} \\
\hline CAG-2 & $0.89(0.83 ; 0.97)$ & 0.006 \\
\hline Average-CAG & $0.89(0.81 ; 0.99)$ & 0.025 \\
\hline \multicolumn{3}{|l|}{ Categorical variable } \\
\hline CAG-2 ( $\geq 23$ vs $<23)$ & $0.64(0.40 ; 1.02)$ & 0.061 \\
\hline Average-CAG ( $\geq 22$ vs $<22)$ & $0.67(0.43 ; 1.05)$ & 0.079 \\
\hline \multicolumn{3}{|c|}{$(G G N)_{n}$ repeat polymorphism in the $A R$ gene } \\
\hline \multicolumn{3}{|c|}{ Continuous variable } \\
\hline GGN-1 & $0.84(0.73 ; 0.96)$ & 0.011 \\
\hline GGN-2 & $0.74(0.60 ; 0.90)$ & 0.002 \\
\hline Average-GGN & $0.75(0.63 ; 0.90)$ & 0.002 \\
\hline \multicolumn{3}{|l|}{ Categorical variable } \\
\hline GGN-1 ( $\geq 23$ vs $<23)$ & $0.59(0.36 ; 0.95)$ & 0.032 \\
\hline GGN-2 $(\geq 23$ vs $<23)$ & $0.32(0.14 ; 0.74)$ & 0.008 \\
\hline Average-GGN ( $\geq 23$ vs $<23)$ & $0.56(0.34 ; 0.90)$ & 0.018 \\
\hline \multicolumn{3}{|l|}{ Single nucleotide polymorphisms } \\
\hline FSHR307 (Ala/Ala versus others) & $1.84(1.02 ; 3.32)$ & 0.042 \\
\hline FSHR307 (G allele versus A allele) & $1.33(0.97 ; 1.82)$ & 0.076 \\
\hline FSHR680 (Ser/Ser versus others) & $1.82(1.02 ; 3.26)$ & 0.042 \\
\hline$P G R+331(A A+G A$ versus $G G)$ & $1.83(0.92 ; 3.64)$ & 0.084 \\
\hline
\end{tabular}

Only results with $P<0.1$ are listed. OR, odds ratio; $\mathrm{Cl}$, confidence interval for $\mathrm{OR}$. 
Table 5 Frequency of the FSHRAla307Thr, FSHRSer680Asn, and PGRG + 331A single nucleotide polymorphisms in the population studied

\begin{tabular}{|c|c|c|c|c|}
\hline Polymorphism & Genotype & Cases & Controls & Overall \\
\hline \multirow[t]{3}{*}{ FSHRAla307Thr } & Ala/Ala & 46 (21.39\%) & $60(17.04 \%)$ & 106 (18.69\%) \\
\hline & Ala/Thr & $106(49.30 \%)$ & $177(50.28 \%)$ & $283(49.91 \%)$ \\
\hline & Thr/Thr & $63(29.30 \%)$ & $115(32.67 \%)$ & 178 (31.39\%) \\
\hline \multirow[t]{3}{*}{ FSHRSer680Asn } & Ser/Ser & $48(22.32 \%)$ & $56(16.76 \%)$ & 107 (18.87\%) \\
\hline & Ser/Asn & $99(46.04 \%)$ & $172(48.86 \%)$ & $271(47.79 \%)$ \\
\hline & Asn/Asn & 68 (31.62\%) & $121(34.37 \%)$ & 189 (33.33\%) \\
\hline \multirow[t]{3}{*}{$P G R G+331 A$} & $\mathrm{~A} / \mathrm{A}$ & $0(0 \%)$ & $1(0.28 \%)$ & $1(0.17 \%)$ \\
\hline & $A / G$ & $32(14.88 \%)$ & $39(9.09 \%)$ & $71(12.52 \%)$ \\
\hline & $\mathrm{G} / \mathrm{G}$ & $183(85.11 \%)$ & $312(88.63 \%)$ & 495 (87.30\%) \\
\hline
\end{tabular}

Women who carried two copies of Ala at position $307(18.69 \%)$ or two copies of Ser at position 680 $(18.87 \%)$ of the FSHR had respectively 1.84 or 1.82 times higher risk of ovarian cancer comparing with other genotypes of the FSHR gene at these positions (Table 4). The same analysis in the group of serous carcinomas showed an increased risk of disease for the Ser/Ser genotype only $(P=0.042$, OR $1.9,95 \%$ CI $(1.02 ; 3.59))$. Carrying at least one Ala or Ser allele was not associated with a higher risk of the disease.

We did not find any associations between the genotype variants at PGRG $+331 \mathrm{~A}$ locus and the risk of ovarian cancer (Table 4).

Analysis of genetic and non-genetic parameters and their influence on clinical outcome for the subgroup of taxane-platinum-treated patients

Results from previous studies suggest that TP53 status may influence clinical value of other molecular factors (Kupryjańczyk et al. 2003, 2004, Ziolkowska et al. 2009). Therefore, evaluation of clinical importance of the studied polymorphisms was performed in all patients treated with taxane-platinum, and in subgroups determined by TP53 immunohistochemical status $(\mathrm{TP} 53(-)$ and TP53(+)), in which TP53(+) means TP53 dysfunction manifested by TP53 protein accumulation; the latter had been determined previously (Kupryjańczyk et al. 2008).

\section{CR and platinum sensitivity}

Among genetic parameters, the FSHRAla307Ala polymorphism showed a tendency to diminish odds of $\mathrm{CR}(P=0.059$, OR 1.0 for other genotypes at FSHR307, OR 0.24 for Ala/Ala, 95\% CI $(0.06 ; 1.06)$ ). Among clinicopathological variables, only RT showed an association with $\mathrm{CR}(P=0.023$, OR 1.0 for RT 0 , OR 0.07 for RT $>0,95 \% \mathrm{CI}(0.01 ; 0.70))$ and platinum sensitivity (PS; $P=0.017$, OR 1.0 for RT 0 , OR 0.12 for $\mathrm{RT}>0$, $95 \%$ CI $(0.02 ; 0.68))$. The analysis in TP53(-) and TP53(+) subgroups did not reveal other significant factors.

\section{DFS and OS}

The most significant influence on DFS and OS was exerted by RT (Table 6). Among genetic parameters, longer $(\geq 23) A R(\mathrm{CAG}) n$ repeats on the longer allele decreased the risk of recurrence by $55 \%(P=0.031)$, while FSHRSer680Ser genotype showed a tendency for the opposite effect (when compared with other genotypes at the FSHR 680 position, $P=0.062$; Table 6). These associations were much stronger in the TP53(+) group $(P=0.003, P=0.037$ for the AR and FSHR polymorphisms respectively; Table 6); they were not observed in the TP53(-) group.

The same polymorphisms showed a similar effect on risk of death, i.e. the FSHRSer680Ser genotype showed a tendency $(P=0.06)$ to increase the risk of death nearly twice in the whole group, while longer ( $\geq 23) A R$ (CAG) $n$ repeats on the longer allele decreased the risk of death by $61 \%(P=0.03)$; the latter association was observed in the TP53 $(+)$ group only (Table 6).

\section{Discussion}

Our study is the first one that shows an association between (GGN) $n$ repeat length polymorphism of the $A R$ gene and ovarian cancer risk; the increase in $(\mathrm{GGN}) n$ repeat was associated with lower risk of ovarian cancer. One previous study concerning this subject brought negative results (Schildkraut et al. 2007). Similarly, although not statistically significant, association was found for prostate cancer (Hsing et al. 2000). The functional significance of (GGN) $n$ repeat length polymorphism is unknown. Complete deletion of the $(\mathrm{GGN}) n$ repeat tract resulted in $30 \%$ reduction of transcriptional activity of the AR (Gao et al. 1996). 

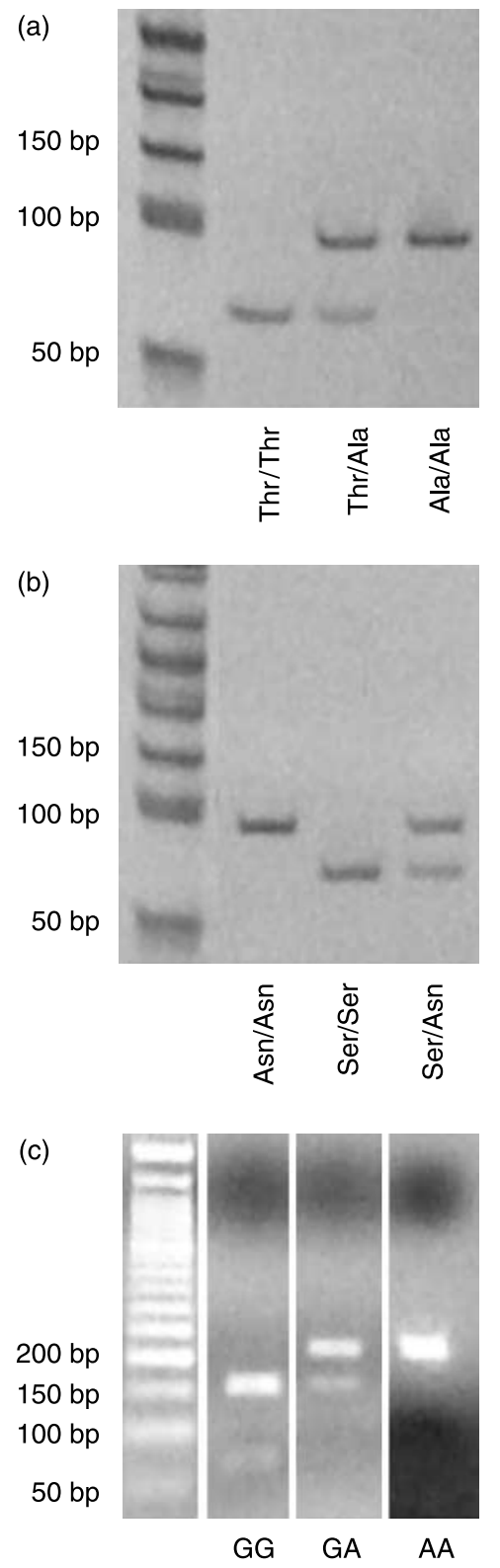

Figure 3 The RFLP pattern of FSHRAla307Thr (a), FSHRSer680Asn (b), and PGRG + 331A (c) SNP showing two types of homozygotes and a heterozygote.

Lundin et al. (2007) states that AR allele with 23 $(\mathrm{GGN}) n$ repeats has the strongest transactivational activity and each change in (GGN) $n$ tract length causes slight impairment of receptor function. Other authors (Ding et al. 2005) state that (GGN)n repeat length affects protein level, not transactivational activity of the receptor and that shorter allele forms produce higher AR protein levels.

The $(\mathrm{CAG}) n$ repeat is the most extensively studied $A R$ gene polymorphism. The experiments on cell lines showed that AR transcriptional activity was reduced by each additional CAG repeat (Buchanan et al. 2004). It was demonstrated that P160-type co-activators influencing receptor activity of the AR bound more strongly to shorter repeats (Irvine et al. 2000). Moreover, La Spada et al. (1991) reported that expansion of (CAG) $n$ repeat to over 40 led to mild androgen insensitivity (Belsham et al. 1992). As androgens may act as mitogens (for example in prostate and ovaries) or as anti-mitogens (in breast), they would exert different effects in different tissues. Consequently, carriers of longer CAG repeats would have a higher risk of developing breast cancer, while having a lower risk of developing prostate or ovarian cancer. Nonetheless, the published results are inconsistent (Ferro et al. 2002). Among African Americans, shorter allele forms increased ovarian cancer risk (Schildkraut et al. 2007); however, no such association was found among Caucasians. Spurdle et al. (2000) could not show the association between CAG repeat length and risk of the disease; nevertheless, their work suggests that longer alleles may be protective against ovarian cancer. Our results support this hypothesis. Nonetheless, there are also results in conflict with the androgen hypothesis showing that longer alleles increase the risk of ovarian cancer (Santarosa et al. 2002, Terry et al. 2005a).

In regard to clinical outcome, Li et al. $(2003,2007)$ reported that ovarian cancer patients with higher number of CAG repeats had a longer time to recurrence or $\mathrm{P}$ and longer OS. Such association was also found for prostate cancer patients (Nam et al. 2000). Our results are in agreement showing a decreased risk of recurrence and death by longer CAG alleles. Because tumor recurrence is due to cancer cell repopulation, these data may suggest that longer CAG alleles are less efficient in stimulation of tumor cell proliferation than shorter alleles. Indeed, recently Li et al. (2008) have shown that ARs modulate EGFR signaling and that shorter CAG repeat alleles promote aggressive phenotype by increasing the abundance of phosphorylated EGFR and MAPK. Stronger associations in the group with TP53 protein accumulation, observed in our study, are in line with our previous results and a hypothesis that proteins stimulating tumor cell proliferation have a greater chance to exert clinical effects in patients with TP53 dysfunctional cancers (Kupryjańczyk et al. 2003, 2004, Kupryjańczyk 2006, Ziolkowska et al. 2009).

Mutations in the FSHR gene are very rare. Nonetheless, their localization corresponds well with the degree of receptor inactivation. Mutations in the extracellular region of the FSHR protein have been 
Table 6 Analysis of disease-free survival and overall survival with respect to TP53 status (Cox proportional hazards model) ${ }^{a}$

\begin{tabular}{|c|c|c|c|c|}
\hline & $\begin{array}{l}\text { All patients }(N=69) \\
\text { HR }(95 \% \mathrm{Cl} \text { for } \mathrm{HR})\end{array}$ & $P$ value & $\begin{array}{l}\text { TP53 }(+) \text { group }(N=35) \\
\text { HR }(95 \% \mathrm{Cl} \text { for } \mathrm{HR})\end{array}$ & $P$ value \\
\hline Overall survival & $N=69,50$ deaths & & $N=35,26$ deaths & \\
\hline FSHR660 other genotypes & 1.0 & & & \\
\hline FSHR660 Ser/Ser & $1.96(0.97 ; 3.97)$ & 0.061 & & \\
\hline \multicolumn{5}{|l|}{ AR-CAG2 } \\
\hline$<23$ & & & 1.0 & \\
\hline$\geq 23$ & & & $0.39(0.17 ; 0.91)$ & 0.030 \\
\hline \multicolumn{5}{|l|}{ Residual tumor size } \\
\hline 0 & 1.0 & & 1.0 & \\
\hline$<0.5$ & & & $18.84(1.89 ; 187.98)$ & 0.012 \\
\hline $0.5<\mathrm{RT} \leq 2 \mathrm{~cm}$ & & & $10.35(0.95 ; 112.05)$ & 0.055 \\
\hline$>2 \mathrm{~cm}$ & $3.39(1.36 ; 8.43)^{b}$ & 0.009 & $17.39(1.86 ; 162.33)$ & 0.012 \\
\hline Tumor grade 2 & 1.0 & & & \\
\hline Tumor grade 3 & $4.74(1.41 ; 15.90)$ & 0.012 & & \\
\hline Tumor grade 4 & $6.54(1.80 ; 23.83)$ & 0.004 & & \\
\hline Disease-free survival & $N=44,39$ recurrences & & $N=24,20$ recurrences & \\
\hline FSHR680 other genotypes & 1.0 & & 1.0 & \\
\hline FSHR680 Ser/Ser & $2.85(0.95 ; 8.53)$ & 0.062 & $5.23(1.11 ; 24.70)$ & 0.037 \\
\hline \multicolumn{5}{|l|}{ AR-CAG2 } \\
\hline$<23$ & 1.0 & & 1.0 & \\
\hline$\geq 23$ & $0.45(0.22 ; 0.93)$ & 0.031 & $0.17(0.05 ; 0.55)$ & 0.003 \\
\hline \multicolumn{5}{|l|}{ Residual tumor size } \\
\hline 0 & 1.0 & & 1.0 & \\
\hline$<0.5$ & $3.80(1.40 ; 10.25)$ & 0.009 & 21.44 (3.02; 152.48) & 0.002 \\
\hline $0.5<\mathrm{RT} \leq 2 \mathrm{~cm}$ & $2.85(0.99 ; 8.19)$ & 0.051 & 26.49 (2.82; 248.68) & 0.004 \\
\hline$>2 \mathrm{~cm}$ & $11.26(3.15 ; 40.23)$ & $<0.001$ & $61.20(5.94 ; 629.99)$ & 0.001 \\
\hline
\end{tabular}

$\mathrm{Cl}$, confidence interval; HR, hazard ratio.

aThe analysis included all polymorphisms and clinicopathological variables studied - only those showing associations or borderline associations are shown. Analysis of TP53(-) group did not reveal any significance of the polymorphisms, despite comparable group size.

${ }^{\mathrm{b}}$ Residual tumor $\geq 2$ vs 0 .

associated with abolished ligand binding and signaling, while mutations in the transmembrane region impair signal transduction (Huhtaniemi \& Alevizaki 2006). The role of FSHR polymorphic variants in ovarian cancer development is not well established. In transfection experiments, no significant differences in binding affinities, FSH-stimulated cAMP, or IP3 production (Simoni et al. 1999, Sudo et al. 2002) between the two receptor variants (Ala307Thr in the extracellular domain and Ser680Asn in the intracellular domain of the protein) have been found; however, the functional differences in vivo have been identified (Perez Mayorga et al. 2000). Our results suggest an association between Ala/Ala307FSHR and Ser/Ser680FSHR polymorphisms and ovarian cancer risk. To date, two publications concerning this issue have been published (Yang et al. 2006, Heubner et al. 2009). Yang et al. showed that homozygous carriers of Ala at position 307 or Ser at position 680 of FSHR protein had significantly higher risk of developing serous and mucinous tumors. Heubner et al. could not find any association between FSHR polymorphisms and ovarian cancer risk.
From the viewpoint of clinical significance, our results also suggest that FSHRAla/Ala genotype at position 307 may diminish chances of CR in patients treated with taxane-platinum agents, while two serines at position 680 of the FSHR protein may increase the risk of recurrence and death. To our knowledge, this is the first time such associations are reported (no association between clinical parameters and course of disease has been found by Heubner et al. (2009)).

The anti-neoplastic effect of progesterone depends on the PGR expression, ligand metabolism, and on tight regulation of the balance between the $\alpha$ - and $\beta$-PGR isoforms. The A allele at position +331 of the $P G R$ gene leads to the formation of PGR- $\beta$ isoform that alone can promote cell growth; thus, this polymorphism is thought to increase ovarian cancer risk. To date, one publication (Risch et al. 2006) has shown a significant connection between $\mathrm{A}$ allele and the disease in postmenopausal women only. In similarity to our study, Romano et al. (2006) observed higher frequency of allele A in ovarian cancer patients. Terry et al. (2005b) and Pearce et al. (2008) did not show any 
association between the studied factors. According to Berchuck et al. (2004), A allele decreased the risk of endometrioid and clear cell ovarian cancers only.

The results of this study are presented and discussed with a limitation that the group of patients analyzed comes from two Warsaw area hospitals and may not be representative of the whole Polish population. Nevertheless, these hospitals treat the vast majority of ovarian cancer patients from central Poland. The lack of histological heterogeneity did not allow us to make analyses in different histological subgroups. However, this homogeneity may be an advantage. We were able to show that these polymorphisms (except for Ala307Thr in FSHR gene) influenced the risk of serous ovarian cancer. Another bias may be introduced by the fact that cases and controls were not matched. The only parameter known was the age and it was different in the two groups analyzed. We tried to minimize this bias by using the logistic regression models with correction for age. Also, the estimated number of controls who might develop ovarian cancer was only 0.1 . Unfortunately, we did not have any epidemiological characteristics but patient's age.

The strength of our study is that we used two different approaches (analyses with continuous and categorized polymorphism variables) in the statistical analysis. This provided a more objective evaluation of the association between repeat polymorphisms and ovarian cancer risk.

In conclusion, our study suggests that the (CAG)n and (GGN) $n$ repeat length polymorphisms of the $A R$ gene and Ala307Thr and Ser680Asn SNPs in the FSHR protein influence ovarian cancer risk in the Polish population. Longer alleles of $(\mathrm{CAG}) n$ or $(\mathrm{GGN}) n$ of the $A R$ gene seem to have a protective effect. The presence of two alleles for Ala or Ser in the mentioned positions of FSHR seems to increase ovarian cancer risk. Longer alleles of (CAG) $n$ may decrease the risk of recurrence and death in taxane-platinum-treated ovarian cancer patients, while FSHRSer680Ser genotype appears to exert the opposite effect. The role of PGR polymorphism is still elusive.

\section{Declaration of interest}

There is no conflict of interest that could be perceived as prejudicing the impartiality of the research reported.

\section{Funding}

This research did not receive any specific grant from any funding agency in the public, commercial, or not-for-profit sector.

\section{Acknowledgements}

The authors wish to thank Beata Uszyńska-Kałuża and all the employees from Blood Center of the Central Hospital of the Ministry of Internal Affaires and Administration in Warsaw for providing control cohort for this study. We would like to thank Dr Joanna Didkowska for her help in epidemiological analysis. The technical assistance of Joanna Moes is acknowledged.

\section{References}

Belsham DD, Yee WC, Greenberg CR \& Wrogemann K 1992 Analysis of the CAG repeat region of the androgen receptor gene in a kindred with X-linked spinal and bulbar muscular atrophy. Journal of Neurological Sciences 112 133-138.

Berchuck A, Schildkraut JM, Wenham RM, Calingaert B, Ali S, Henriott A, Halabi S, Rodriguez GC, Gertig D, Purdie DM et al. 2004 Progesterone receptor promoter +331 A polymorphism is associated with a reduced risk of endometrioid and clear cell ovarian cancers. Cancer Epidemiology, Biomarkers and Prevention 13 2141-2147.

Buchanan G, Yang M, Cheong A, Harris JM, Irvine RA, Lambert PF, Moore NL, Raynor M, Neufing PJ, Coetzee GA et al. 2004 Structural and functional consequences of glutamine tract variation in the androgen receptor. Human Molecular Genetics 13 1677-1692.

Chamberlain NL, Driver ED \& Miesfeld RL 1994 The length and location of CAG trinucleotide repeats in the androgen receptor $\mathrm{N}$-terminal domain affect transactivation function. Nucleic Acids Research 22 3181-3186.

Christian MC \& Trimble EL 1994 Salvage chemotherapy for epithelial ovarian carcinoma. Gynecologic Oncology 55 S143-S150.

Cramer DW \& Welch WR 1983 Determinants of ovarian cancer risk. II. Inferences regarding pathogenesis. Journal of the National Cancer Institute 71 717-721.

Didkowska J, Wojciechowska U, Tarkowski W \& Zatonski W 2007 Cancer in Poland in 2005, p 143. Warsaw, Poland: Institute of Oncology.

Ding D, Xu L, Menon M, Reddy GP \& Barrack ER 2005 Effect of GGC (glycine) repeat length polymorphism in the human androgen receptor on androgen action. Prostate 62 133-139.

Fathalla MF 1971 Incessant ovulation - a factor in ovarian neoplasia? Lancet 2163.

Ferro P, Catalano MG, Dell'Eva R, Fortunati N \& Pfeffer U 2002 The androgen receptor CAG repeat: a modifier of carcinogenesis? Molecular and Cellular Endocrinology 193 109-120.

Gao T, Marcelli M \& McPhaul MJ 1996 Transcriptional activation and transient expression of the human androgen receptor. Journal of Steroid Biochemistry and Molecular Biology 59 9-20. 
Heubner M, Riemann K, Otterbach F, Kimmig R, Kasimir-Bauer S, Siffert W \& Wimberger P 2009 The haplotype of two FSHR polymorphisms in ovarian cancer - a potential role of ethnology in risk modification. Gynecologic Oncology 112 486-489.

Hsing AW, Gao YT, Wu G, Wang X, Deng J, Chen YL, Sesterhenn IA, Mostofi FK, Benichou J \& Chang C 2000 Polymorphic CAG and GGN repeat lengths in the androgen receptor gene and prostate cancer risk: a population-based case-control study in China. Cancer Research 60 5111-5116.

Huhtaniemi I \& Alevizaki M 2006 Gonadotrophin resistance. Best Practice and Research. Clinical Endocrinology and Metabolism 20 561-576.

Irvine RA, Ma H, Yu MC, Ross RK, Stallcup MR \& Coetzee GA 2000 Inhibition of p160-mediated coactivation with increasing androgen receptor polyglutamine length. Human Molecular Genetics 9 267-274.

Kupryjańczyk J 2006 Why TP53 status does not associate with clinical endpoints in ovarian cancer: facts and hypotheses. Gynecologic Oncology 100 5-7.

Kupryjańczyk J, Szymańska T, Madry R, Timorek A, Stelmachów J, Karpińska G, Rembiszewska A, Ziółkowska I, Kraszewska E, Debniak J et al. 2003 Evaluation of clinical significance of TP53, BCL-2, BAX and MEK1 expression in 229 ovarian carcinomas treated with platinum-based regimen. British Journal of Cancer 88 848-854.

Kupryjańczyk J, Madry R, Plisiecka-Hałasa J, Bar J, Kraszewska E, Ziółkowska I, Timorek A, Stelmachów J, Emerich J, Jedryka M et al. 2004 TP53 status determines clinical significance of ERBB2 expression in ovarian cancer. British Journal of Cancer 91 1916-1923.

Kupryjańczyk J, Kraszewska E, Ziolkowska-Seta I, Madry R, Timorek A, Markowska J, Stelmachow J, Bidzinski M \& Pocsg PO 2008 TP53 status and taxane-platinum versus platinum-based therapy in ovarian cancer patients: a nonrandomized retrospective study. BMC Cancer 827.

Li AJ, Baldwin RL \& Karlan BY 2003 Short androgen receptor allele length is a poor prognostic factor in epithelial ovarian carcinoma. Clinical Cancer Research 9 3667-3673.

Li AJ, Elmore RG, Pavelka JC \& Karlan BY 2007

Hyperandrogenism, mediated by obesity and receptor polymorphisms, promotes aggressive epithelial ovarian cancer biology. Gynecologic Oncology 107 420-423.

Li AJ, Scoles DR, Armstrong KU \& Karlan BY 2008 Androgen receptor cytosine-adenine-guanine repeat polymorphisms modulate EGFR signaling in epithelial ovarian carcinomas. Gynecologic Oncology 109 220-225.

Lundin KB, Giwercman A, Dizeyi N \& Giwercman YL 2007 Functional in vitro characterisation of the androgen receptor GGN polymorphism. Molecular and Cellular Endocrinology 264 184-187.
Miller AB, Hoogstraten B, Staquet M \& Winkler A 1981 Reporting results of cancer treatment. Cancer 47 207-214.

Modugno F 2004 Ovarian cancer and polymorphisms in the androgen and progesterone receptor genes: a HuGE review. American Journal of Epidemiology 159 319-335.

Nam RK, Elhaji Y, Krahn MD, Hakimi J, Ho M, Chu W, Sweet J, Trachtenberg J, Jewett MA \& Narod SA 2000 Significance of the CAG repeat polymorphism of the androgen receptor gene in prostate cancer progression. Journal of Urology 164 567-572.

Pearce CL, Wu AH, Gayther SA, Bale AE, Beck PA, Beesley J, Chanock S, Cramer DW, DiCioccio R, Edwards R et al. 2008 Progesterone receptor variation and risk of ovarian cancer is limited to the invasive endometrioid subtype: results from the Ovarian Cancer Association Consortium pooled analysis. British Journal of Cancer 98 282-288.

Perez Mayorga M, Gromoll J, Behre HM, Gassner C, Nieschlag E \& Simoni M 2000 Ovarian response to follicle-stimulating hormone (FSH) stimulation depends on the FSH receptor genotype. Journal of Clinical Endocrinology and Metabolism 85 3365-3369.

Rao BR \& Slotman BJ 1991 Endocrine factors in common epithelial ovarian cancer. Endocrine Reviews 12 14-26.

Risch HA 1998 Hormonal etiology of epithelial ovarian cancer, with a hypothesis concerning the role of androgens and progesterone. Journal of the National Cancer Institute 90 1774-1786.

Risch HA, Bale AE, Beck PA \& Zheng W 2006 PGR + 331 $\mathrm{A} / \mathrm{G}$ and increased risk of epithelial ovarian cancer. Cancer Epidemiology, Biomarkers and Prevention 15 1738-1741.

Romano A, Lindsey PJ, Fischer DC, Delvoux B, Paulussen AD, Janssen RG \& Kieback DG 2006 Two functionally relevant polymorphisms in the human progesterone receptor gene $(+331 \mathrm{G} / \mathrm{A}$ and progins) and the predisposition for breast and/or ovarian cancer. Gynecologic Oncology 101 287-295.

Santarosa M, Bidoli E, Gallo A, Steffan A, Boiocchi M \& Viel A 2002 Polymorphic CAG repeat length within the androgen receptor gene: identification of a subgroup of patients with increased risk of ovarian cancer. Oncology Reports 9 639-644.

Schildkraut JM, Murphy SK, Palmieri RT, Iversen E, Moorman PG, Huang Z, Halabi S, Calingaert B, Gusberg A, Marks JR et al. 2007 Trinucleotide repeat polymorphisms in the androgen receptor gene and risk of ovarian cancer. Cancer Epidemiology, Biomarkers and Prevention 16 473-480.

Simoni M, Gromoll J, Hoppner W, Kamischke A, Krafft T, Stahle D \& Nieschlag E 1999 Mutational analysis of the follicle-stimulating hormone $(\mathrm{FSH})$ receptor in normal and infertile men: identification and 
characterization of two discrete FSH receptor isoforms. Journal of Clinical Endocrinology and Metabolism 84 751-755.

La Spada AR, Wilson EM, Lubahn DB, Harding AE \& Fischbeck KH 1991 Androgen receptor gene mutations in $\mathrm{X}$-linked spinal and bulbar muscular atrophy. Nature $\mathbf{3 5 2}$ 77-79.

Spurdle AB, Webb PM, Chen X, Martin NG, Giles GG, Hopper JL \& Chenevix-Trench G 2000 Androgen receptor exon $1 \mathrm{CAG}$ repeat length and risk of ovarian cancer. International Journal of Cancer 87 637-643.

Sudo S, Kudo M, Wada S, Sato O, Hsueh AJ \& Fujimoto S 2002 Genetic and functional analyses of polymorphisms in the human FSH receptor gene. Molecular Human Reproduction 8 893-899.

Tavassoli AF \& Devilee P 2003 Pathology of Genetics of Tumors of Breast and Female Genital Organs. WHO Classification of Tumors. Lyon, France: IARC Press.

Terry KL, De Vivo I, Titus-Ernstoff L, Shih MC \& Cramer DW $2005 a$ Androgen receptor cytosine, adenine, guanine repeats, and haplotypes in relation to ovarian cancer risk. Cancer Research 65 5974-5981.
Terry KL, De Vivo I, Titus-Ernstoff L, Sluss PM \& Cramer DW $2005 b$ Genetic variation in the progesterone receptor gene and ovarian cancer risk. American Journal of Epidemiology $161442-451$.

De Vivo I, Huggins GS, Hankinson SE, Lescault PJ, Boezen M, Colditz GA \& Hunter DJ 2002 A functional polymorphism in the promoter of the progesterone receptor gene associated with endometrial cancer risk. PNAS 99 12263-12268.

Wooster R \& Weber BL 2003 Breast and ovarian cancer. New England Journal of Medicine 348 2339-2347.

Yang CQ, Chan KY, Ngan HY, Khoo US, Chiu PM, Chan QK, Xue WC \& Cheung AN 2006 Single nucleotide polymorphisms of follicle-stimulating hormone receptor are associated with ovarian cancer susceptibility. Carcinogenesis 27 1502-1506.

Ziółkowska-Seta I, Madry R, Kraszewska E, Szymańska T, Timorek A, Rembiszewska A \& Kupryjańczyk J 2009 TP53, BCL-2 and BAX analysis in 199 ovarian cancer patients treated with taxane-platinum regimens. Gynecologic Oncology 112 179-184. 